\title{
On sceptics and enthusiasts: What are the expectations towards self-driving cars?
}

\author{
Nielsen, Thomas Alexander Sick; Haustein, Sonja
}

Published in:

Transport Policy

Link to article, DOI:

10.1016/j.tranpol.2018.03.004

Publication date:

2018

Document Version

Peer reviewed version

Link back to DTU Orbit

Citation (APA):

Nielsen, T. A. S., \& Haustein, S. (2018). On sceptics and enthusiasts: What are the expectations towards selfdriving cars? Transport Policy, 66, 49-55. https://doi.org/10.1016/j.tranpol.2018.03.004

\section{General rights}

Copyright and moral rights for the publications made accessible in the public portal are retained by the authors and/or other copyright owners and it is a condition of accessing publications that users recognise and abide by the legal requirements associated with these rights.

- Users may download and print one copy of any publication from the public portal for the purpose of private study or research.

- You may not further distribute the material or use it for any profit-making activity or commercial gain

- You may freely distribute the URL identifying the publication in the public portal

If you believe that this document breaches copyright please contact us providing details, and we will remove access to the work immediately and investigate your claim 


\title{
On sceptics and enthusiasts: What are the expectations towards self-driving cars?
}

\section{Thomas A. Sick Nielsen}

The Danish Road Directorate, Niels Juels Gade 13, 1022 København, Denmark, tasn@vd.dk

\section{Sonja Haustein*}

Department of Management Engineering, Technical University of Denmark, Diplomvej 372, 2800 Kgs. Lyngby, Denmark, sonh@dtu.dk

* Corresponding author

\begin{abstract}
Automation in transport is increasing rapidly. While it is assumed that automated driving will have a significant impact on travel demand, the nature of this impact is not clear yet. Based on an online survey $(N=3040)$, this study explores the expected consequences of automated driving in the Danish population. Participants were divided into three homogeneous segments based on attitudes towards automated and conventional car driving: Sceptics (38\%); Indifferent stressed drivers (37\%) and Enthusiasts (25\%). The attitudinal segments differ in their socio-demographic profiles, current travel behaviour, interest in usecases for self-driving cars, and anticipated changes of behaviour in a future with self-driving cars. People who are enthusiastic about self-driving cars are typically male, young, highly educated, and live in large urban areas, while Sceptics are older, car reliant and more often live in less densely populated areas. The indifferent group consists of more car reluctant people. The expected advantages of self-driving cars generally resemble the aspects highlighted in other studies, such as relief from driving tasks and the possibility of doing other things while travelling, with some variation between the three segments. Preferred future scenarios include car ownership rather than sharing solutions as well as residential relocation, which is considered by $22 \%$ of all participants as a consequence of the possibility of working in the car (13\% of Sceptics; $28 \%$ of Enthusiasts). All in all, increased travel demand can be expected from an uptake of increasingly automated cars, which will be realised in the different segments with different speeds, depending on policies, business models, and proven functionality and safety.
\end{abstract}

\section{Keywords}

Automated driving, Automated vehicles, User acceptance, Attitude, Segmentation, Travel demand

\section{Highlights}

- Three attitudinal segments were divided: Sceptics; Indifferent stressed drivers, and Enthusiasts.

- Enthusiasts are typically male, young, highly educated, and live in large urban areas.

- Sceptics are older, the most car reliant and more often live in less densely populated areas.

- Expected advantages of self-driving cars and behavioural change differ between the segments.

- All in all, the uptake of automated cars is expected to increase travel demand. 


\section{Introduction}

Transport planning and research is increasingly focussing on automated driving and its potential effects on transport behaviour and infrastructure. While still difficult to grasp and assess, many researchers expect significant changes within the planning horizons associated with infrastructure decisions that are taken today. Thus, for transport planning there is an urge to develop scenarios for transport automation. Academic publications and publications from a public policy perspective have developed scenarios for the adoption of automated driving based on historical adoption rates of new technologies or general societal change assumptions (Levinson et al., 2016; Milakis et al., 2017). Other studies have focused on the likely effects of automated driving on traffic flow and infrastructure performance in terms of delay and capacity (Aria et al., 2016; Department for Transport, 2016). However, the methodologies for assessing the behavioural responses to automated transport are weakly established and the forecasting of future options that very few have experienced calls for a widening of the methodologies applied. This includes considering the public's expectations towards automated or self-driving cars as an indication of how the transformation towards automation could develop. Knowledge about the public's expectations can also help to refine estimations of adoption rates and speeds as among the most important variables when it comes to foreseeing the effects on the transport system.

Researchers have been working on explanatory frameworks and have adopted models to assess automation uptake and its acceptance, including the Technology Acceptance Model (Davis, 1989), and frameworks presenting a wider set of possible associations (Ghazizadek et al., 2012; Nordhoff et al., 2016). As Nordhoff et al. (2016) suggest, multiple psychological, situational and socio-economic factors influence acceptance. These include: expected performance, expectations about one's own efforts, social influences, pleasure related to driving, perceived control, the level of automation, the vehicle type and quality, techsavviness/interest, driving impairments, productivity of driving time, past and current driving experiences, sensation-seeking behaviour, the level of trust, the traffic situations/use-case for automated driving, and socio-economic levels. Only a few of these factors have been included in acceptance studies until now. Following Becker and Axhausen (2017), results point towards effects of gender, age, income, awareness of automation trends, and level of autonomy in the current vehicle as correlates of acceptance towards automated driving. Men and younger individuals are more likely to accept autonomous driving, whereas higher incomes imply a higher willingness to pay. Awareness of and experience with automation in vehicles are also positively related to acceptance. Additional factors that are suggested to affect acceptance include level of urbanisation and the monotony of the current driving tasks.

According to Payre et al. (2014) and Bjørner (2017), the preferred use-cases for automated driving are highway driving in congested conditions as well as parking the car. In addition, it is generally assumed that disability or physical conditions prohibiting driving are key factors for interest in or acceptance of automated driving (e.g., Saripalli, 2017). However, according to Fraedrich et al.'s (2016) empirical results, people with mobility impairment do not have a special interest in self-driving cars - their willingness to use them is even lower than that of people without mobility impairment.

Beside Nordhoff et al. (2016), the studies of Zmud et al. (2016), Lavieri et al. (2017) and Lee et al. (2017) point towards the importance of attitudinal and lifestyle factors, including social support and affinity for technology, for the expectations towards the adoption of automated driving. In addition to individual factors, cultural factors also seem to play a relevant role, as studies indicate strong differences between 
countries with respect to concerns with the technology (Kyriakidis et al., 2015) as well as in the interest in using automated driving (Schoettle \& Sivak, 2014; Lang et al., 2016). People in high-income countries, for instance, show more concern with vehicle data transmission (Kyriakidis et al., 2015). With regard to general acceptance, $85 \%$ of Indian and around $75 \%$ of Chinese consumers indicate that they would take a ride in a fully self-driving car, while only $36 \%$ of Japanese and around $40 \%$ of German and Dutch consumers indicate the same. In France, the UK and the US, acceptance is around 50\% (Lang et al., 2016). The different levels of acceptance may be related to the anticipated advantages as compared to conventional car driving, evaluated on the background of the existing transport system and related problems such as congestion, accident risk, and pollution (Lang et al., 2016).

As it is still unknown what the key 'drivers' or determinants of automated driving are, there is a need for more research on user acceptance or interest in automated driving - including results from different countries.

This paper contributes to the state of knowledge by studying the acceptance of automated driving and related expectations in the Danish population. Besides considering the population as a whole, we divide it into homogeneous segments based on attitudes towards automated and conventional car driving. The attitudinal segments are characterised by their socio-demographic profiles, travel behaviour, interest in use-cases for self-driving cars, and the respondents' anticipated change of behaviour in a future with selfdriving cars. Showing the relationship of attitudinal sub-groups to other variables makes the results transferable to other countries and provides more insights into possible future scenarios than results based on the Danish population as a whole.

\section{Method}

\subsection{Sample and procedure}

Data for this study were collected in November and December 2016 via an online survey carried out for the Danish Road Directorate by Wilke (Vejdirektoratet and Wilke, 2017). The target population were adults 18 years or older. A sample of 3040 people was drawn from 35,000 members of Wilke's online survey panel. The panel is continuously recruited through several channels including social media, telephone and face-toface contact to allow representation of the diversity of the Danish population. The sampling was further stratified to reflect the composition of the Danish population with respect to age, gender and region of residence. The sample consisted of 1526 women and 1514 men, aged 18-89 years.

\subsection{Measures}

In the following section, we describe the parts of the questionnaire that were analysed in the present study.

Car access and travel patterns: Respondents were asked how many cars they had in the household and if they had a driving licence. They were further asked how often they used different modes of transport ( $1=$ "daily"; 6 = "never") and those with a car in the household were asked for which of the following purposes they typically used the car: commuting to work; leisure activities, sport and shopping; holiday; driving for the fun of it (cruising). 
Interest and attitudes towards self-driving cars: To define self-driving cars, a fully self-driving vehicle scenario was presented to the participants, which was an adapted version of the scenario used by Lang et al. (2016) for their study of expectations towards self-driving cars across different countries. The description included pictures of different variants of self-driving cars and stated, inter alia, that these cars would be able to drive even without a driver/passenger. On the basis of this scenario, people were asked to assess how much they agreed with different aspects of self-driving cars and conventional cars on a fivepoint Likert scale ( $1=$ "totally disagree"; $5=$ "totally agree"). Items included both positive and negative expectations about self-driving cars and items measuring car excitement and car stress (see Table 1 for a list of items). Participants were further asked which of eleven potential advantages of self-driving cars they expected (see Table 5). On a five-point Likert scale participants were asked to assess their interest in different forms of self-driving vehicles, such as self-driving taxis with or without a back-up driver (1="not interested at all"; $5=$ "very interested"), and how likely it was that they would use / buy a self-driving car when available (1="very unlikely"; 5="very likely"; see Table 6).

Expectations towards fully automated vehicles: Respondents were asked how they expected their car use to change when having a self-driving car ( $1=$ "drive much less"; $5=$ "drive much more"), whether they expected to use the car more for specific purposes and whether they expected to move farther away from the city because of the possibility of working in the car. The questions were partly based on the behavioural adaptations reported from the semi-structured interviews by Zmud et al. (2016). Finally, expectations of the year when self-driving cars would become available on the Danish car market were requested.

Background information included age, gender, education, income, household size and place of residence. In addition, general technology acceptance was assessed with one item. This item was adopted from Rogers' (2003) innovation scale as a measure to generally assess the respondents' interest in using new technologies.

\subsection{Analysis}

In transport research and practice, the segmentation of transport users into sub-groups based on attitudinal variables is often used to describe varying user needs and expectations (e.g., Siren \& Haustein, 2013) and as a basis for more targeted interventions (see Haustein \& Hunecke, 2013 for an overview). Based on their attitudes towards self-driving cars and conventional cars, we divided the population into segments by means of cluster analysis (see Section 3.1). In a preliminary step, the number of attitudes was reduced to their underlying dimensions based on a principal component analysis (PCA). Based on the results of the PCA, mean scales were calculated, which then served as the input variables for the cluster analysis. We conducted cluster analyses using the k-means algorithm for two to five cluster solutions. We compared the four different cluster solutions according to the criteria of predictive power and interpretability. To assess predictive power, we used the intention to buy and use a self-driving car as an external criterion variable.

The identified segments were compared based on demographics, travel patterns, interests and expectations with regard to self-driving cars. Group differences were tested based on a $\mathrm{Chi}^{2}$ test, KruskalWallis $\mathrm{H}$-tests, and ANOVAs, depending on the scale of measurement. Differences within a group were tested by Wilcoxon tests. 


\section{Results}

In this section, we first describe how we divided the population into segments and how the resulting clusters are defined. After that, we describe the segments' expectations with regard to self-driving cars: what advantages do they see (if any); what kind of self-driving services would they be most interested in; do they intend to buy a self-driving car and in what way would that affect their mobility? Finally, we present the segments' expectations of the year when self-driving cars will become available.

\subsection{Segmentation}

As a preparation for the cluster analysis, the large number of attitudes first had to be reduced to their underlying dimensions. For this purpose, a principal component analysis with varimax rotation was carried out based on attitudes towards conventional and self-driving cars. Retaining only factors with Eigenvalues greater than one, a 3 -factor solution was obtained, which explained $54 \%$ of the variance. Table 1 presents the loadings of the single items on the three factors. On factor 1 ("scepticism") items that express concern and scepticism towards automated driving have the highest loadings. Items with high loadings on factor two ("enthusiasm") express fascination and positive expectation with regard to self-driving cars. On factor three ("driving stress") items that express stress in relation to conventional car driving load positive, while items related to positive car experience load negative. Three mean scales were created, each composed of the items with loadings above 0.6 on the related factor. All three scales showed acceptable internal consistencies, with Cronbach's alpha above 0.7 (see Table 1). 
Table 1. Results of a principal component analysis on attitudes towards conventional and self-driving cars

\begin{tabular}{|c|c|c|c|}
\hline & Factor 1 & Factor 2 & Factor 3 \\
\hline & Scepticism & Enthusiasm & Car stress \\
\hline I am worried that I will lose my driving skills. & 691 & -.171 & -.051 \\
\hline $\begin{array}{l}\text { I am worried about the legal responsibility in the case of } \\
\text { an accident. }\end{array}$ & .688 & -.048 & .060 \\
\hline $\begin{array}{l}\text { I am worried about software hacking and other forms of } \\
\text { abuse. }\end{array}$ & .684 & -.058 & .079 \\
\hline $\begin{array}{l}\text { I am worried that it will make driving less enjoyable and } \\
\text { make me feel less in control. }\end{array}$ & .663 & -.282 & -.272 \\
\hline $\begin{array}{l}\text { I am worried about general safety and don't trust these } \\
\text { technologies. }\end{array}$ & .628 & -.385 & .098 \\
\hline $\begin{array}{l}\text { I am worried that it will be difficult to make spontaneous } \\
\text { changes to a trip. }\end{array}$ & .613 & -.202 & -.107 \\
\hline I experience personal freedom, when I drive a car. ${ }^{a}$ & .406 & .093 & -.639 \\
\hline It's a pleasure to drive a car as it is today. ${ }^{a}$ & .390 & -.021 & -.688 \\
\hline I feel stressed when driving. & .121 & .098 & .752 \\
\hline I perceive it as increasingly stressful to drive a car. & .080 & .249 & .712 \\
\hline For me, the car is only a way to get from $A$ to $B$. & .083 & .044 & .517 \\
\hline $\begin{array}{l}\text { In } 30 \text { years, fully self-driving cars will be so advanced that } \\
\text { it will be irresponsible to drive manually. }\end{array}$ & -.008 & .665 & .106 \\
\hline The idea of fully self-driving cars is silly. ${ }^{a}$ & .398 & -.686 & .027 \\
\hline The idea of fully self-driving cars is fascinating. & -.114 & .835 & .051 \\
\hline It would be a pleasure to drive in a fully self-driving car. & -.190 & .805 & .151 \\
\hline $\begin{array}{l}\text { I would feel safe driving in a fully self-driving car without a } \\
\text { steering wheel. }\end{array}$ & -.277 & .672 & .097 \\
\hline Explained variance & 20.37 & 19.35 & 14.84 \\
\hline Cronbach's alpha (including items with loadings $\geq .6$ ) & 79 & .83 & 72 \\
\hline
\end{tabular}

Note. ${ }^{\text {a }}$ item was recoded when calculating the mean scale.

As the second step towards segmentation, cluster analyses were conducted based on the k-means algorithms. We conducted analyses for 2- to 5 -cluster solutions based on the three mean scales (scepticism, enthusiasm, car stress). Then, we compared the four cluster solutions with regard to group differences in an external criterion variable, namely the intention to buy/use an automated car. As the results in Table 2 show, Eta ${ }^{2}$ values continuously increase with the increasing number of clusters, while the $F$-values decrease. Based on this criterion, none of the solutions is clearly superior to the others. 
Table 2. ANOVA results for different cluster solutions

\begin{tabular}{lll}
\hline & \multicolumn{2}{l}{ ANOVAs (Intention to buy/use a self-driving car by cluster variable) } \\
\hline Number of clusters & F-value & Eta $^{2}$ \\
\hline 2 & $925,67^{* * *}$ & .252 \\
3 & $629.40^{* * *}$ & .314 \\
4 & $528.81^{* * *}$ & .366 \\
5 & $418.38^{* * *}$ & .379 \\
\hline
\end{tabular}

Note. ${ }^{* * *} p<.001$

As the main criterion, we used the interpretation of the cluster solutions. The 2-cluster solution resulted in one cluster representing people who were sceptical about automated cars and one cluster including people who were more enthusiastic about automated cars but with a less positive attitude towards conventional driving. In the 3-cluster solution, the profile of the sceptics remained relatively stable, while with the "indifferent" group a new cluster appeared mainly by splitting up the enthusiasts. In the 4-cluster solution, the profiles of the three earlier clusters remained nearly the same, while now an additional indifferent cluster appeared that showed a more positive attitude towards conventional driving. In the 5-cluster solution, a variant of the sceptics appeared with a more negative attitude towards driving. The profiles of the 3-cluster solution could also be identified in the 4- and 5-cluster solutions, where they were supplemented by smaller clusters, which we considered less relevant in the context of this paper. Thus, we selected the more parsimonious 3-cluster solution as the final cluster solution.

Table 3 provides the means of the three clusters on the three attitudinal scales.

Table 3. Description of clusters based on attitudinal scales

\begin{tabular}{llllllll}
\hline & \multicolumn{2}{c}{ Sceptics $(n=1164)$} & \multicolumn{2}{l}{$\begin{array}{l}\text { Indifferent stressed } \\
\text { drivers }(n=1125)\end{array}$} & \multicolumn{2}{l}{ Enthusiasts $(n=750)$} & ANOVAs \\
\hline & $M$ & $S D$ & $M$ & $S D$ & $M$ & $S D$ & F-value \\
\hline Scepticism & 3.84 & 0.54 & 3.27 & 0.53 & 2.64 & 0.59 & $1050.63^{\star \star \star}$ \\
Enthusiasm & 2.41 & 0.66 & 3.12 & 0.49 & 4.05 & 0.49 & $1901.82^{\star \star \star}$ \\
Car stress & 1.91 & 0.52 & 3.00 & 0.49 & 2.41 & 0.70 & $1091.45^{\star \star \star}$ \\
\hline
\end{tabular}

Note. ${ }^{* *} p<.001$. Mean differences between all clusters were tested in post hoc tests (Bonferroni corrected) showing that all clusters differed from each other significantly in each attitude dimension ( $p<$ $.001)$.

The results show that Sceptics have significantly higher concerns regarding self-driving cars and a significantly lower degree of enthusiasm than the other two clusters. As the low score in car stress shows, they are the group with the most positive attitude towards conventional car driving and feel least stressed about driving.

By contrast, Indifferent stressed drivers are the group with the most negative attitude towards conventional driving and take a middle position with regard to enthusiasm and scepticism towards self-driving cars. Thus, members of this segment are indifferent about automated driving and comparably stressed when using 
conventional cars. Finally, Enthusiasts, the smallest of the three clusters, form the group that is most excited and fascinated about self-driving cars and has the fewest concerns about them. With regard to their attitude towards driving in a conventional car, they lie in between the other two groups.

\subsection{What are the cluster members' characteristics?}

Table 4 shows how the clusters differ with regard to demographic variables, technology acceptance, car access and travel patterns. While Sceptics are on average older than members of both other groups and live more often outside the capital region of Denmark, Enthusiasts are most often male and most often have a university degree. Indifferent stressed drivers are closer to Enthusiasts with regard to age distribution and residential region, but closer to Sceptics with regard to gender distribution.

With regard to general technology acceptance, Enthusiasts describe themselves as more open for new technologies: the percentage of people who like to try out new technologies is $2-3$ times higher than in the other two clusters. 
Table 4. Differences of clusters in demographics and travel patterns

\begin{tabular}{|c|c|c|c|c|c|c|}
\hline & & Sceptics & Indifferent & Enthusiasts & all & $\begin{array}{c}p \text { (Chi }^{2} \text { test; } \\
H \text {-test) }\end{array}$ \\
\hline Gender & Men & $45.3 \%$ & $45.7 \%$ & $64.6 \%$ & $50.2 \%$ & $<.001$ \\
\hline \multirow[t]{6}{*}{ Age } & $18-29$ & $18.1 \%$ & $22.9 \%$ & $22.0 \%$ & $21.0 \%$ & \multirow{6}{*}{$<.001$} \\
\hline & $30-39$ & $12.3 \%$ & $19.2 \%$ & $16.8 \%$ & $16.1 \%$ & \\
\hline & $40-49$ & $19.1 \%$ & $20.0 \%$ & $18.5 \%$ & $19.3 \%$ & \\
\hline & $50-59$ & $20.3 \%$ & $16.1 \%$ & $19.4 \%$ & $18.4 \%$ & \\
\hline & $60-69$ & $20.3 \%$ & $14.2 \%$ & $16.9 \%$ & $17.0 \%$ & \\
\hline & $70+$ & $9.9 \%$ & $7.6 \%$ & $6.4 \%$ & $8.2 \%$ & \\
\hline Education & University education & $44.2 \%$ & $49.2 \%$ & $56.2 \%$ & $49.1 \%$ & $<.001$ \\
\hline Region & Capital region & $27.7 \%$ & $38.1 \%$ & $42.3 \%$ & $35.4 \%$ & $<.001$ \\
\hline \multirow[t]{4}{*}{$\begin{array}{l}\text { Technology } \\
\text { acceptance }\end{array}$} & $\begin{array}{l}\text { I like to try new } \\
\text { technologies when they } \\
\text { are under development. } \\
\text { I am the first one to try } \\
\text { new technologies when } \\
\text { they appear on the } \\
\text { market. }\end{array}$ & $4.6 \%$ & $6.7 \%$ & $14.7 \%$ & $10.6 \%$ & \multirow[t]{4}{*}{$<.001$} \\
\hline & $\begin{array}{l}\text { I try new technologies } \\
\text { when others do. }\end{array}$ & $35.9 \%$ & $36.2 \%$ & $43.4 \%$ & $37.9 \%$ & \\
\hline & $\begin{array}{l}\text { I try out new technologies } \\
\text { when the majority has } \\
\text { already tested them. }\end{array}$ & $32.5 \%$ & $26.8 \%$ & $18.1 \%$ & $26.7 \%$ & \\
\hline & $\begin{array}{l}\text { I do not feel the need to } \\
\text { try out new technologies. }\end{array}$ & $19.9 \%$ & $20.9 \%$ & $6.3 \%$ & $16.9 \%$ & \\
\hline \multirow{2}{*}{$\begin{array}{l}\text { Car access \& } \\
\text { equipment }\end{array}$} & Car in the household & $70.2 \%$ & $49.2 \%$ & $64.1 \%$ & $60.4 \%$ & $<.001$ \\
\hline & Driving licence & $91.3 \%$ & $75.6 \%$ & $88.6 \%$ & $84.4 \%$ & $<.001$ \\
\hline \multirow{4}{*}{$\begin{array}{l}\text { Car (as driver } \\
\text { or passenger) } \\
\text { typically used } \\
\text { for...) }\end{array}$} & Commuting to work & $54.7 \%$ & $58.2 \%$ & $59.6 \%$ & $57.1 \%$ & .18 \\
\hline & Leisure, shopping, sport & $85.1 \%$ & $73.9 \%$ & $85.6 \%$ & $81.6 \%$ & $<.001$ \\
\hline & Holiday & $41.4 \%$ & $35.0 \%$ & $45.1 \%$ & $40.3 \%$ & $<.01$ \\
\hline & Cruising & $38.6 \%$ & $29.8 \%$ & $32.9 \%$ & $34.3 \%$ & $<.01$ \\
\hline \multirow[t]{4}{*}{$\begin{array}{l}\text { Transport } \\
\text { forms }\end{array}$} & $\begin{array}{l}\text { Car as driver (almost) } \\
\text { daily }\end{array}$ & $45.1 \%$ & $28.5 \%$ & $40.9 \%$ & $37.5 \%$ & $<.001$ \\
\hline & Cycling (almost) daily & $22.6 \%$ & $31.3 \%$ & $31.0 \%$ & $28.1 \%$ & $<.001$ \\
\hline & $\begin{array}{l}\text { Public transport (almost) } \\
\text { daily }\end{array}$ & $8.9 \%$ & $16.7 \%$ & $11.7 \%$ & $12.7 \%$ & $<.001$ \\
\hline & Taxi, less than monthly & $93.9 \%$ & $88.3 \%$ & $89.2 \%$ & $90.5 \%$ & $<.001$ \\
\hline
\end{tabular}

The results with regard to car access indicate that the Indifferents' neutral position on self-driving cars may at least partly result from their more limited car access, as only half of them have a car in the household and only three-quarters hold a driving licence. However, this could also be a result of their comparable negative attitude towards driving - the cause and effect relation cannot be answered based on correlational data. Persons with a car in the household were asked for which purposes they typically use 
the car. While there was no significant difference in the percentage who use the car for commuting to work, a lower percentage of Indifferents use the car for other travel purposes, while more Sceptics drive just for the fun of it ("cruising") and more Enthusiasts use it to get to their holiday destination. A higher share of Sceptics (45\%) drive on a daily basis as compared to Enthusiasts (41\%) and in particular Indifferents (29\%), who drive the least. Almost one third of the Indifferents and Enthusiasts cycle on a daily basis, while it is less than one quarter of Sceptics. Almost twice as many Indifferents use public transport on a daily basis as compared to Sceptics. The travel patterns reflect the Sceptics' positive and the Indifferents' negative attitudes towards driving as well as the Sceptics' residential location.

\subsection{What are the clusters' interests and expectations with regard to self-driving cars?}

When asked what advantages participants see in driving a self-driving car (see Table 5), the aspects most people see are that they arrive relaxed at their destination (38\%), do not have to park the car (35\%), and are able to use the time for other activities (34\%). In contrast, only a minority (12\%) expect to save travel time.

Table 5. Expected advantages of fully self-driving cars (SAE level 5) by cluster

\begin{tabular}{lrrrc}
\hline & Sceptics & Indifferent & Enthusiasts & all \\
\hline I will arrive relaxed at my destination. & $26.2 \%$ & $33.7 \%$ & $60.9 \%$ & $37.7 \%$ \\
I will not have to park the car myself. & $26.1 \%$ & $33.4 \%$ & $49.0 \%$ & $34.6 \%$ \\
I can do other activities while travelling. & $24.0 \%$ & $29.3 \%$ & $56.8 \%$ & $34.1 \%$ \\
I will be relieved from paying attention to traffic. & $20.3 \%$ & $27.2 \%$ & $53.8 \%$ & $31.3 \%$ \\
It will be possible to drive under the influence of alcohol or & $27.5 \%$ & $24.5 \%$ & $44.5 \%$ & $30.5 \%$ \\
medication. & $17.2 \%$ & $23.0 \%$ & $47.2 \%$ & $26.9 \%$ \\
It will benefit the environment. & $18.7 \%$ & $21.1 \%$ & $41.3 \%$ & $25.2 \%$ \\
It will decrease fuel consumption. & $7.4 \%$ & $20.7 \%$ & $56.8 \%$ & $24.8 \%$ \\
It will increase safety. & $15.0 \%$ & $20.4 \%$ & $35.5 \%$ & $22.2 \%$ \\
It will be possible to drive without a driving licence. & $7.7 \%$ & $14.7 \%$ & $39.6 \%$ & $18.3 \%$ \\
It will optimize the use of cars. & $4.5 \%$ & $10.2 \%$ & $25.9 \%$ & $12.0 \%$ \\
It will increase my travel speed. & $38.1 \%$ & $26.0 \%$ & $3.5 \%$ & $24.8 \%$ \\
\hline None of these & & & &
\end{tabular}

Note. All group differences are significant in $\mathrm{Chi}^{2}$ tests, $p<.001$.

An advantage that is often stressed in the media about self-driving cars is the possible increase of road safety. However, only every fourth participant agrees that driving an automated car is safer. When looking at the differences between the three clusters, we find that Sceptics see the fewest advantages in automated cars, followed by Indifferent stressed drivers and Enthusiasts. In most cases, the Indifferent cluster is closer to Sceptics than to Enthusiasts. The only aspect where Sceptics agree slightly more than the Indifferents is that one may drive under the influence of alcohol or medicine, which might be related to the older age of Sceptics and related to a higher likelihood of depending on medicine that affects driving. Anticipated safety benefits are the aspect on which Sceptics differ the most from Enthusiasts: $7.4 \%$ of Sceptics as opposed to $56.8 \%$ of Enthusiasts indicate increased safety as an advantage associated with fully self-driving cars. 
Participants were further asked about their interest in different use-cases for self-driving cars (see Table 6). As expected, Enthusiasts are most interested in all the suggested use-cases, while Sceptics are the least interested. Overall, the highest interest was shown in the use of self-driving cars for short rides. The biggest differences can be found in the intention to own a self-driving car. Group differences are smaller for the option where a back-up person is still available. For Sceptics and Indifferents, driving in a self-driving taxi with a back-up person is significantly more attractive than driving in taxi without a driver (Wilcoxon test, $p<$ $.001)$, while for Enthusiasts it is more attractive without a driver $(p<.001)$. For all groups it is more attractive to drive to work alone in a self-driving car than to drive together with others. However, the differences are less pronounced for Sceptics and Indifferents than for Enthusiasts.

Table 6. Interest in use-cases for fully self-driving cars and intention to use and buy a self-driving car by cluster

\begin{tabular}{|c|c|c|c|c|}
\hline & Sceptics & Indifferent & Enthusiasts & all \\
\hline Self-driving taxis without driver & 1.93 & 2.62 & 3.47 & 2.59 \\
\hline Self-driving taxis with a backup driver & 2.32 & 2.88 & 3.19 & 2.75 \\
\hline $\begin{array}{l}\text { Travel to place of work, education or similar alone in } \\
\text { a self-driving car }\end{array}$ & 2.15 & 2.97 & 3.76 & 2.89 \\
\hline $\begin{array}{l}\text { Travel to place of work or education in a self-driving } \\
\text { carpool/van with other passengers }\end{array}$ & 2.06 & 2.85 & 3.33 & 2.70 \\
\hline Owning a self-driving vehicle & 2.00 & 2.86 & 3.85 & 2.81 \\
\hline Use shared self-driving cars for everyday travel & 1.88 & 2.72 & 3.20 & 2.54 \\
\hline $\begin{array}{l}\text { Use self-driving cars for short rides (e.g. from the } \\
\text { airport terminal to your own car on the parking lot) }\end{array}$ & 2.75 & 3.18 & 3.79 & 3.19 \\
\hline Ride in a self-driving bus without driver & 1.97 & 2.75 & 3.47 & 2.65 \\
\hline $\begin{array}{l}\text { Will you use a fully self-driving car when this } \\
\text { becomes possible? }\end{array}$ & 2.15 & 3.00 & 4.01 & 2.95 \\
\hline $\begin{array}{l}\text { Will you buy a fully self-driving car, when this } \\
\text { becomes possible? }\end{array}$ & 1.81 & 2.56 & 3.45 & 2.51 \\
\hline
\end{tabular}

Note. Means on a scale 5-point Likert scale; all group differences significant in ANOVAs, $p<.001$

When asked how access to a self-driving car would change their mobility, the percentage of people who do not expect to change their car use frequency is largest in all groups (see Table 7). However, a comparably high share of Enthusiasts expect to drive more, while a comparably higher share of Sceptics expect to drive less. The Indifferents again lie in between these two groups. Similar differences, though less pronounced, can be found for different purposes of car use. With regard to residential mobility, every fifth person can imagine moving farther away from the city as the self-driving car allows them to work in the car. This percentage is significantly higher for Enthusiasts, where it is more than every fourth person. 
Table 7. Expected changes due to having a self-driving car by cluster

\begin{tabular}{|c|c|c|c|c|c|c|}
\hline & & Sceptics & Indifferent & Enthusiasts & all & $\begin{array}{c}p \\
\left(\text { Chi }^{2} \text { test }\right)\end{array}$ \\
\hline \multirow{4}{*}{$\begin{array}{l}\text { Expected changes in } \\
\text { driving frequency due } \\
\text { to self-driving car }\end{array}$} & drive (much) more & $7.8 \%$ & $20.1 \%$ & $33.5 \%$ & $19.0 \%$ & \multirow{4}{*}{$<.001$} \\
\hline & unchanged & $51.0 \%$ & $44.5 \%$ & $57.8 \%$ & $50.1 \%$ & \\
\hline & drive (much) less & $12.5 \%$ & $4.5 \%$ & $0.9 \%$ & $6.5 \%$ & \\
\hline & don't know & $28.6 \%$ & $30.8 \%$ & $7.8 \%$ & $24.4 \%$ & \\
\hline $\begin{array}{l}\text { Use the car more for } \\
\text { everyday purposes }\end{array}$ & yes & $43.0 \%$ & $51.0 \%$ & $58.6 \%$ & $53.1 \%$ & $<.05$ \\
\hline $\begin{array}{l}\text { Use the car more for } \\
\text { holidays }\end{array}$ & yes & $45.3 \%$ & $50.6 \%$ & $57.8 \%$ & $52.9 \%$ & .086 \\
\hline $\begin{array}{l}\text { Expect to move farther } \\
\text { away from the city (as } \\
\text { working in car) }\end{array}$ & yes & $12.9 \%$ & $17.7 \%$ & $28.1 \%$ & $21.5 \%$ & $<.01$ \\
\hline
\end{tabular}

Finally, participants were asked in an open question when they expected self-driving cars to become reality (see Figure 1). The medium year of the total sample is 2030; that is, half of the participants expect that fully self-driving cars will be available in Denmark by 2030 or before. Among Enthusiasts it is $58 \%$ who expect self-driving cars to become reality at the latest by 2030 , while this is only the case for $42 \%$ of Indifferents and $30 \%$ of Sceptics. $42 \%$ of Sceptics do not expect self-driving cars on the market before $2050-$ if at all.

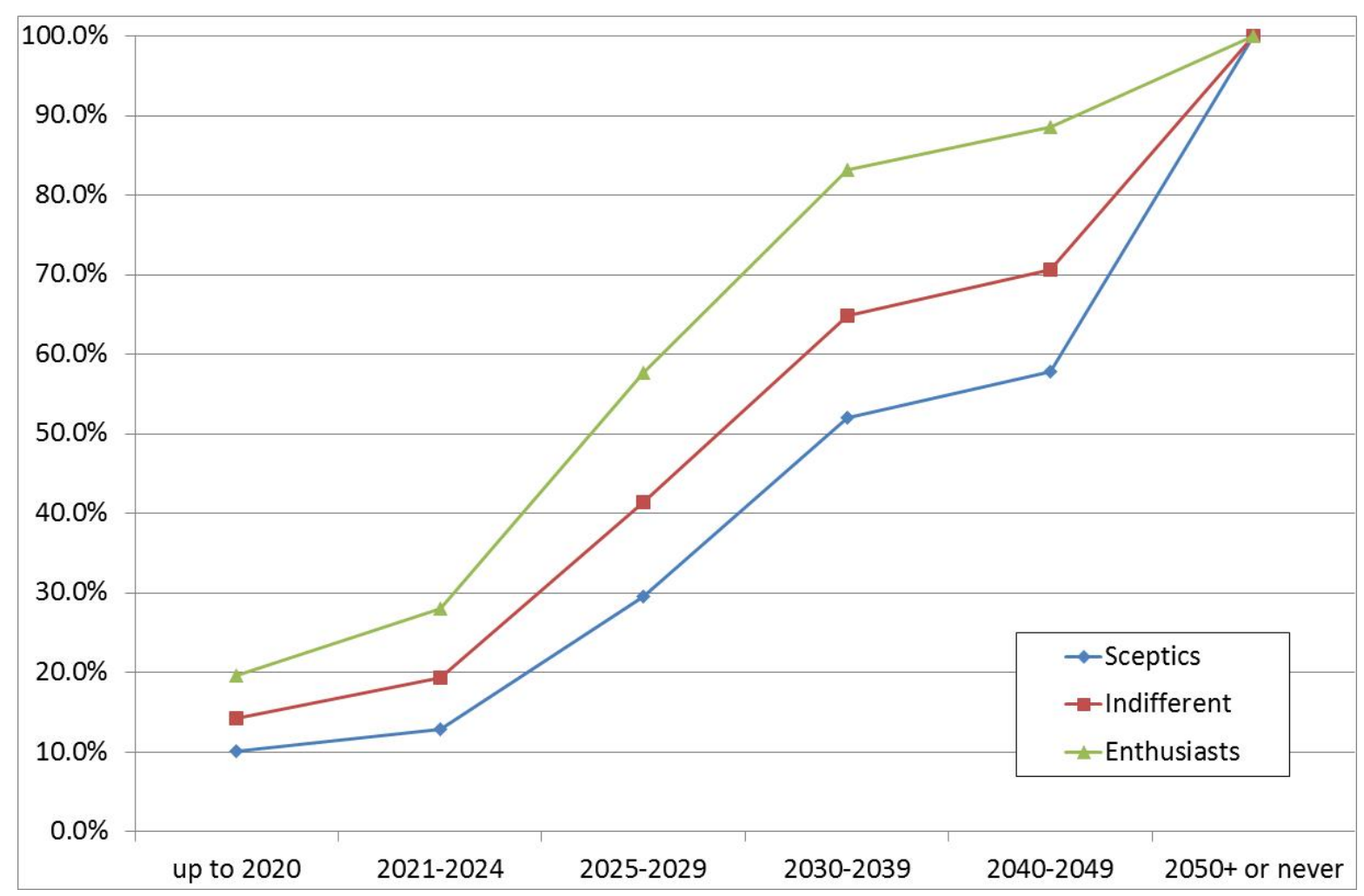

Figure 1. Expectations of when self-driving cars will be available on the market by clusters (cumulative percentages) 


\section{Discussion and conclusions}

In this study, we explored Danes' expectations with regard to self-driving cars. Based on driving attitudes and attitudes towards self-driving cars, we distinguished three segments, namely people who are sceptical about self-driving cars, people who are enthusiastic and people who are indifferent. While we expect the size of the different segments to differ across countries, we think that the group characteristics including the relation to other variables can be generalised - at least to European countries with a similar mobility culture to that of Denmark, such as Germany and the Netherlands (Haustein \& Nielsen, 2016).

People who are enthusiastic about self-driving cars are typically male, younger and live more often in metropolitan areas, while Sceptics are older and more often live in less densely populated areas. The indifferent group consists of more people who do not own a car, who have comparable negative attitudes towards driving and find it rather stressful to drive. While one might imagine that they see self-driving cars as an opportunity to reduce their driving stress, this does not seem to be the case. This might result from their higher reluctance to adopt new technologies, which might include considering the interaction with self-driving cars as rather frightening and connected with feelings of loss of control. "Powerlessness" has been identified as a relevant emotion associated with self-driving cars in other studies (Fraedrich et al., 2016).

The Sceptics' negative opinion about self-driving cars is related to their positive attitude towards conventional driving. For these people, driving is associated with excitement and freedom and means more than going from $A$ to $B$, to which driving would be reduced when using a self-driving car. Sceptics are not only afraid of losing their driving excitement but are also more sceptical about possible advantages, such as time-saving, safety and environmental benefits, while they focus more on the potential problems and dangers of self-driving cars.

The socio-demographic profile of the Enthusiasts, who are more likely to be male, young, to live in a large urban area, and to have a higher education level, reflects findings from other acceptance studies (Becker \& Axhausen, 2017). With respect to the current transport behaviour, Enthusiasts are less likely to own a car and to drive daily compared to the Sceptics. This is likely to reflect their urban living space and they could be described as urban drivers who combine driving with other modes, but are more likely to own a car and less likely to use public transport than the Indifferents. The combination of driving and an urban living space would also imply that Enthusiasts have more experience with driving in congested conditions, which again would reflect the findings from other studies (e.g., Payre et al., 2014).

The expected advantages of self-driving cars in the full sample resemble the distribution in Lang et al.'s (2016) global sample. Relief from driving tasks and the possibility of doing other things while travelling are at the top of the list. Key differences among the segments include that while $97 \%$ of the Enthusiasts acknowledge the advantages of self-driving cars, this only applies to $62 \%$ of the Sceptics. Within each segment the relief from driving tasks is among the most acknowledged advantages, but Enthusiasts as opposed to Sceptics also include increased safety as a highly acknowledged advantage, while the possibility of driving under the influence of alcohol or medication tops the list among Sceptics. Seeing the main advantage of fully self-driving cars in uses where manual driving is not possible due to physical impairment of the traveller, or in the cases where manual driving would be illegal due to the influence of alcohol or medication, indicates a distance and a considerable reluctance to embrace the self-driving revolution - 
compared to Enthusiasts and Indifferents. It may also reflect the higher percentage of older drivers among Sceptics, who are more likely to suffer from diseases that may at some point prevent them from manual driving, so that self-driving cars could be regarded as a way to maintain current mobility levels despite stopping driving. That they are sceptical despite these possible advantages reflects the findings from other recent studies, according to which older or mobility-impaired people show very limited enthusiasm for selfdriving cars as a solution to their needs (e.g., Fraedrich et al., 2016; Shergold et al., 2016).

The interest in different use-cases for self-driving cars also differs substantially between the three segments. The use of self-driving cars (shuttles) within a facility such as an airport ranks high within all three segments, but Enthusiasts would rather own a self-driving vehicle and declare their interest in using fully self-driving cars for everyday purposes as well as self-driving taxis and buses. Sceptics, being less interested overall in the use of self-driving cars, point to the use-case of an airport facility (connecting parking to terminal areas) as their preferred use-case, followed by taxis with backup-drivers. When comparing ownership with shared fleets, all three segments as of today see themselves as being more interested in ownership than shared use, and the shared use-case overall is among the least preferred. This is interesting, as many observers of the field see a shift from private vehicles towards shared fleets as a likely outcome of the development towards increasing automation in transport. The view of the respondents is of course limited by their knowledge and experience of automated transport (see also Cyganski et al., 2015), but still gives an indication that increasing use of shared fleets is likely to require wider changes to the transport system than the advent of the autonomous car. Shared fleets may eventually be maintained to offer additional advantages to their users, such as low overall costs and freedom from the maintenance of vehicles, but how the attributes of such offers will be perceived and appreciated by users is still not known.

Under the precondition of future access to a self-driving car, the Sceptics' reluctance towards the concept leads them to be more likely to respond that they will drive less, whereas a third of the Enthusiasts respond that they would drive more or much more. The Indifferents are more likely to respond that they would drive more - rather than less, but are also less radical than the Enthusiasts. The increased driving would, according to the respondents, be caused by increased driving for everyday purposes, holidays, as well as changes in the location of their residence vis-à-vis urban areas or the place of work. Holiday habits are just as likely to be affected as everyday transport. Expectations towards increased holiday travel or longdistance travel resemble findings from U.S. studies (Zmud et al., 2016; Gurumurthy et al., 2018). The main difference between the segments is that Enthusiasts with self-driving cars expect to do more of everything, and in particular they are much more likely than the other segments to think that they would use the selfdriving car to live farther away from urban areas or their place of work. This scenario is of course limited by the omission of other factors that might change, including travel speeds and time-use in transport, but it does indicate an interest in exploiting the relief from driving tasks and the possibility of doing other things while travelling to modify the geography of home and work.

Understanding and modelling these processes and effects will be critical for strategic planning in relation to increasing automation in transport. An interesting question in this context is why it is regarded as such a great advantage to work in the car that a relevant share of people would even consider moving because of that, when it is an advantage that public transport already offers today: in Denmark most bus and train services offer free Wifi and good possibilities to work while travelling. All groups', but in particular 
Enthusiasts', higher acceptance of the drive-alone and car ownership scenarios as compared to sharing concepts indicates that privacy and status may play a relevant role here.

The results of this study supplement the assessment of the uptake of self-driving cars based on other methodologies such as historical data, economic and general models for the dispersal of new technologies. Enthusiasts, the younger male drivers in the largest urban areas, are likely to be the first buyers of selfdriving cars if they can afford them. The other segments may be more reluctant depending on policies, business models, as well as a proven record of safe functionality for self-driving vehicles. Indifferent stressed drivers could probably first be convinced when they experience that driving a highly automated car actually reduces driving stress, which may first be the case when cars are fully automated. By contrast, for Sceptics driving fun decreases with an increasing level of automation and it would be a relevant feature for them to keep the option of manual driving. For both segments, clear advantages on a societal level may be needed to (partly) compensate for losing individual benefits.

Presuming an uptake of self-driving functionality, increased travel demand is to be expected as a consequence and it will therefore be important to assess the nature of this demand as well as its interaction with demand management strategies and tools. It will also be necessary to monitor the field as use-cases and experiences become more widespread. Self-driving cars are still something that most have no experience of. Driverless shuttles are now used in multiple experiments and evidence from their use within limited domains will gradually become available (see Salonen, 2018), but this needs to be supplemented with studies of the demand for fully and highly automated driving at higher speeds and its impacts. Studies simulating access to fully self-driving cars via offering a free chauffeur service appear to be a promising way to obtain more detailed behavioural data than studies using hypothetical scenarios that people are not familiar with. While a recent study applying such a more naturalistic approach finds a large increase in mileage and number of trips (Harb et al., 2018), one has to take into account that feelings of control and safety are not addressed in the same way when a chauffeur is used. Thus, until fully functioning self-driving cars are available on the market, a combination of different research approaches seems most relevant to enable a realistic estimation on the demand side. 


\section{References}

Aria, E., Olstam, J., Schwietering, C. (2016) 'Investigation of automated vehicle effects on driver's behaviour and traffic performance', Transportation Research Procedia, 15, pp. 761-770.

Becker, F., Axhausen, K. (2017) 'Literature review on behavioural experiments for autonomous vehicles'. Proceedings of the $96^{\text {th }}$ Annual Meeting of the Transportation Research Board, Washington D.C.

Bjørner, T. (2017) 'Driving pleasure and perceptions of the transition from no automation to full self-driving automation', Applied Mobilities, 2(1), pp. 1-16.

Cyganski, R., Fraedrich, E., Lenz, B. (2015) 'Travel-time valuation for automated driving: a use-case-driven study'. Proceedings of the $94^{\text {th }}$ Annual Meeting of the Transportation Research Board, Washington D.C.

Davis, F. D. (1989) 'Perceived usefulness, perceived ease of use, and user acceptance of information technology', MIS Quarterly, 13 (3), pp. 319-340, doi:10.2307/249008

Department for Transport (2016) 'Research on the Impacts of Connected and Autonomous Vehicles (CAVs) on Traffic Flow', Atkins for the Department for Transport, London, https://www.gov.uk/government/publications/driverless-vehicles-impacts-on-traffic-flow

Fraedrich, E., Cyganski, R., Wolf, I., Lenz, B. (2016) 'User Perspectives on Autonomous Driving: A Use-CaseDriven Study in Germany'. Arbeitsberichte, 187, Geographisches Institut, Humboldt-Universität zu Berlin, Available from:

http://elib.dlr.de/103242/1/Fraedrich_Cyganski_Wolf_Lenz_2016_User\%20perspectives\%20on\%20autono mous\%20driving.pdf, last accessed 2018-01-31.

Ghazizadek, M., Lee, J.D., Boyle, L.N. (2012) 'Extending the technology acceptance model to assess automation', Cognition Technology and Work, 14, pp. 39-49.

Gurumurthy, K.M., Kockelman, K.M., Hahm, H. (2018) 'Deeper understanding of Americans' autonomous vehicle preferences: questions on long-distance travel, ride-sharing, privacy, \& crash ethics'. Paper presented at the $97^{\text {th }}$ Annual Meeting of the Transportation Research Board, Washington D.C.

Harb, M., Xiao, Y., Cirella, G., Mokhtarian, P. L., Walker, J. L. (2018) ‘Projecting Travelers into a world of SelfDriving Vehicles: Estimating Travel Behaviour Implications via a Naturalistic Experiment’. Paper presented at the $97^{\text {th }}$ Annual Meeting of the Transportation Research Board, Washington D.C.

Haustein, S., Hunecke, M. (2013) 'Identifying target groups for environmentally sustainable transport: assessment of different segmentation approaches', Current Opinion in Environmental Sustainability, 5(2), pp. 197-204.

Haustein, S., Nielsen, T. A. S. (2016) 'European mobility cultures: A survey-based cluster analysis across 28 European countries', Journal of Transport Geography, 54, pp. 173-180.

Kyriakidis, M., Happee, R., de Winter, J.C.F. (2015) 'Public opinion on automated driving: results of an international questionnaire among 5000 respondents', Transportation Research Part F, 32, pp. 127-140.

Lang, N., Rüssmann, M., Mei-Pochtler, A., Dauner, T., Komiya, S., Mosquet, X., Doubara, X. (2016) Selfdriving vehicles, robo-taxis, and the urban mobility revolution, The Boston Consulting Group and World Economic Forum, Boston. 
Lavieri, P.S., Garikapati, V.M., Bhat, C.R., Pendyla, R.M., Astroza, S., Dias, F.F. (2017) 'Modeling individual preferences for ownership and sharing of autonomous vehicle technologies'. Proceedings of the $96^{\text {th }}$ Annual Meeting of the Transportation Research Board, Washington D.C.

Lee, C., Ward, C., Raue, M., D’Ambrosio, L., \& Coughlin, J. F. (2017). 'Age Differences in Acceptance of Selfdriving Cars: A Survey of Perceptions and Attitudes'. In International Conference on Human Aspects of IT for the Aged Population (pp. 3-13). Springer.

Levinson, D., Boies, A., Cao, J., Fan, Y. (2016) 'The Transportation futures project: Planning for technology change'. Minnesota Department of Transportation, St. Paul.

Milakis, D., Snelder, M., van Arem, B., van Wee, G.P., Correia, G.H. de A. (2017). 'Development of automated vehicles in the Netherlands: scenarios for 2030 and 2050', EJTIR, 17(1), pp. 63-85.

Nordhoff, S., van Arem, B., Happee, R. (2016) 'A conceptual model to explain, predict, and improve use acceptance of driverless vehicles'. Proceedings of the $95^{\text {th }}$ Annual Meeting of the Transportation Research Board, Washington D.C.

Payre, W., Cestac, J., Delhomme, P. (2014) 'Intention to use a fully automated car: Attitudes and a priori acceptability', Transportation Research Part F, 27, pp. 252-263.

Rogers, E. M. (2003) Diffusion of Innovations (5th ed.), New York, Free Press.

Salonen, A.O. (2018) 'Passengers' subjective traffic safety, in-vehicle security and emergency management in the driverless shuttle bus in Finland', Transport Policy, 61, pp. 106-110.

Saripalli, S. (2017) 'Are self-driving cars the future of mobility for disabled people?' The Conversation, Oct. 6, 2017, Available from: https://theconversation.com/are-self-driving-cars-the-future-of-mobility-fordisabled-people-84037, last accessed 2018-02-03.

Schoettle, B., Sivak, M. (2014) Public opinion about self-driving vehicles in China, India, Japan, the U.S., the U.K., and Australia, University of Michigan, Transportation Research Institute, Ann Arbor.

Shergold, I., Wilson, M. and Parkhurst, G. (2016) 'The mobility of older people, and the future role of Connected Autonomous Vehicles. Project Report'. Centre for Transport and Society, University of the West of England, Bristol. Available from: http://eprints.uwe.ac.uk/31998, last accessed 2018-01-26.

Siren, A., Haustein, S. (2013) 'Baby boomers' mobility patterns and preferences: What are the implications for future transport?' Transport Policy, 29, pp. 136-144.

Vejdirektoratet, Wilke (2017) Danskernes forventninger til selvkørende biler, Available from: http://www.vejdirektoratet.dk/DA/viden og data/temaer/Selvkoerendebiler/Documents/Rapport 070217 short.pdf , last accessed 2017-04-11.

Zmud, J., Sener, I.N., Wagner, J. (2016) Consumer acceptance and travel behavior impacts of automated vehicles, Texas A\&M Transportation Institute, Transportation Policy Research Center, College Station. 